\title{
An Analysis of Internally Funded Learning and Teaching Project Evaluation in Higher Education
}

\section{Introduction: Context and Literature Review}

Higher education institutions across the world are under growing pressures from external factors such as growth of students, internationalization and changes in world economy. There is also growing emphasis on accountability of the public funding of Australian universities (Shah et al., 2011) and indeed universities worldwide (Frolich, 2011). Project evaluation is one example of a process that can achieve this accountability by providing empirical evidence to substantiate recommendations for improvements and justification for funding (Stufflebeam, 2011). However, evaluation is a process that is inherently complex, and which remains contested. (Oliver et al., 2002).

The evaluation literature is extensive and diverse, with many journals and conferences devoted to the subject. Within higher education there is an extant body of work on the evaluation of products, programs, processes and, of course, the evaluation of teaching and of curriculum. The literature tends towards descriptions of the evaluation processes, guidelines on what to do and what not to do, and the benefits involved (Chesterton and Cummings, 2007; Phillips, 2002; Stevens et al., 1993). A recent critical review of the literature reveals there is little written on the evaluation of learning and teaching projects in the higher education sector (Huber and Harvey, 2013). That review of the evaluation of learning and teaching projects determined that there is some evidence in the literature that project evaluation is not being carried out in a systematic way in the higher education sector (Alexander and Hedberg, 1994; Alexander, 1999; Bearman et. al., 2008; Cybulski, 2010). However Huber and Harvey (2013) found a lack of evidence based research to explain why this is so. 
Learning and teaching projects in the higher education sector are often funded via grants from two main sources, internal (funded by the local institution) or external (through a large funding body). Requirements for evaluation differ according to each funding body with the scope often related to accountability and the size of the funding which can be upwards of $\$ 100,000$ for external and up to $\$ 20,000$ for internal grants. Correspondingly, project durations tend towards 18-24 months for externally funded projects and 12-18 for internal projects. These latter projects can be administered institutionally or at a department or faculty level, and tend not to explicitly state the scope or method of evaluation required, only that it should exist in some way. It is also often a condition of funding that projects conduct some form of interim or progress evaluation, as well as a final report.

A seminal Australian national study of 104 teaching and development grants found that 'In approximately $90 \%$ of cases, the project leaders reported having had the intention of improving student learning outcomes, but only one third were able to report this as the actual outcome' (Alexander, 1999, p. 173). Subsequently, this study instigated a national audit of funded learning and teaching projects (Southwell et al., 2005). With a focus on dissemination, five conditions for successful dissemination of project findings were identified. Of interest to this paper is that each acknowledged the role of evaluation, for example 'those responsible for the project may require assistance in designing an appropriate evaluation process' (ibid, p. 55), and 'support for quality processes, particularly monitoring and evaluation ought to be supplied' and 'that evaluation is reported within an evaluation framework' (ibid, p. 71). There is no evidence in the literature that progress has been made towards achieving the five conditions (Huber and Harvey, 2013), nor is there evidence on how internally funded projects are being evaluated. 
The current study is designed as an exploratory study into how learning and teaching project evaluation is being approached in the higher education sector using the case of one large, metropolitan university. This university has approximately 39,000 students and 2,800 staff (2013 annual report - institution name withheld for review purposes) and funds a range of learning and teaching projects each year through a competitive grant system. Application guidelines specifically ask for information on evaluation to be considered with the question 'What processes are built into the Project to enable it to be evaluated?'

The following research questions frame this study:

- What evaluation forms and approaches have been used in funded learning and teaching projects at one university?

- What is the project leaders' understanding of evaluation?

- Is there alignment between evaluation theory and practice?

\section{Theoretical Framework}

\section{Evaluation versus research}

Before any discussion on the possible paradigms available for this research study, it is necessary to clarify the distinction between research and evaluation. One could say the goal of research is generalizable knowledge whereas the purpose of evaluation is context-specific (Alkin and Taut, 2003). Researchers ask their own questions in order to seek conclusions they can use to add to the existing body of knowledge. Evaluation answers questions that are important to a particular person or project, for example the stakeholder or client, thus research seeks conclusions and evaluation leads to decisions (Alkin, 2011). 


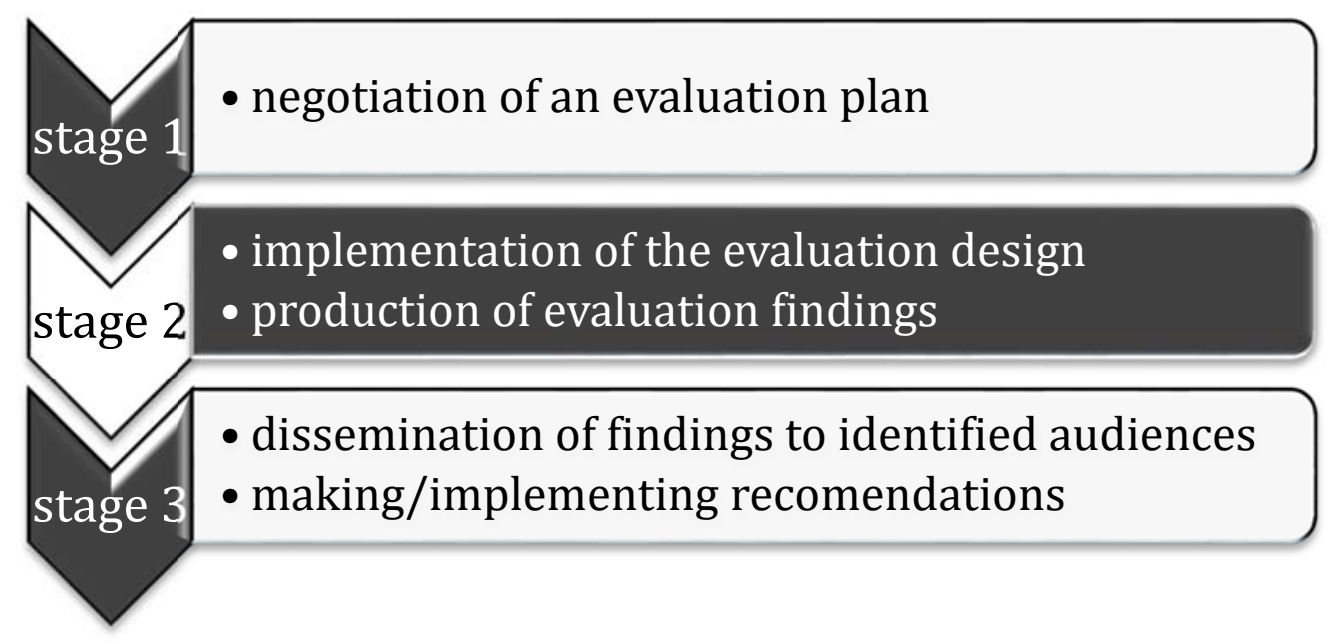

Figure 1. Three stages of Evaluative Enquiry (Owen, 2006)

If we break down evaluative enquiry into its simplest form, we see three component parts (see Figure 1): the development of an evaluation plan through negotiation with stakeholders (which includes setting the key evaluation questions, data collection methods, and criteria to judge against); implementation of the evaluation design and production of findings; and dissemination of findings to identified audiences (Owen, 2006, p. 19).

There is a subtle distinction between evaluation and research and this can be demonstrated by looking at each stage of the process in more detail. The elements within the evaluation plan (stage 1, Figure 1), are usually negotiated or sometimes even imposed upon, in an evaluation. This may also be the case in Action Research (McNiff, 2001) but not usual in other research methods.

Stage 2 (Figure 1) of evaluative enquiry may use similar approaches to the data collection and analysis techniques of research. For example interview or focus group protocols, thematic analysis etc. The communicating stage (stage 3, Figure 1) is when dissemination of findings occurs. With evaluation, a report would highlight the 
judgements that have been made (against the given criteria). A research study reports on the factual findings and offers analysis and interpretation.

Whilst there are subtle differences between evaluation and research, there are also similarities and as such, we can extrapolate that the theoretical worldviews or paradigms prevalent in social science research can also be applied to evaluative enquiry.

\section{Paradigms of enquiry}

There are various paradigms of enquiry in which to frame a research study on evaluation, with Post-positivist and Constructivist being the two most commonly used in practice (Owen, 2006). Studies however do not usually fall neatly into such categorizations and as a result, a third enquiry paradigm, known as emergent realism (ibid), has been gaining ground with evaluation theorists. Realism is

a common-sense ontology in the sense that it takes seriously the existence of the things, structures and mechanisms revealed by the sciences at different levels of reality ... the task of science is precisely to explain 'facts' in terms of more fundamental structures, and in the process it may reveal some of these 'facts' ... to be, in part, illusions ... we may not yet, and never finally, know whether it is true or false (Outhwaite, 1987, pp. 19-20, as cited in Kazi, 2003).

Emergent realism, also known as Pragmatism, is typically associated with Mixed Methods research since 'importance is placed on the questions asked rather than the methods used' (Creswell and Plano-Clark, 2011, p. 41). Furthermore, emergent realists do not insist that theirs is the only form of evaluative enquiry; on the contrary this paradigm encourages other forms and approaches to evaluation (Mark et al., 1998). Proponents of a pragmatic approach to mixed-methods designs state the importance of 'practicality, contextual responsiveness and consequentiality' as important factors for 
success (Datta, 1997, p. 44). The emergent realism/ pragmatism paradigm will frame this research study since it aims to employ a mixed methods approach and investigate 'what works, for whom and in what contexts'.

Whilst there are many examples of the use of pragmatism in the literature on evaluative enquiries of educational programs (Mark and Shotland, 1987), there is minimal literature on learning and teaching project evaluation, and the few that exist do not state anything about the worldviews from which they stem. The research and findings presented in this paper begin to redress this identified gap in the literature and contribute new knowledge to this field.

\section{Research Methodology}

The pragmatic approach recognises that a mix of research methodologies can be employed as "the choice of methodological techniques follows from the questions asked, not vice versa' (Owen, 2006, p.89). Acknowledging the discussion on research being an integral part of evaluation, we adopt a research methodology that aligns with evaluative enquiry methods. We investigate what approaches to evaluation have been used in learning and teaching projects, what the project leaders understandings are of evaluation and whether there is alignment between evaluation theory and practice, using an Action Research approach (McNiff, 2001). This method aligns with developmental evaluation whereby a study is planned, enacted, evaluated and reflected upon (Patton, 1994)

\section{Research Design}

The emergent realism paradigm invites the use of complementary quantitative and qualitative data. To achieve this a convergent parallel design (Creswell and Plano-Clark, 2011) was adopted. 
Two main steps made up the data collection phase. Step one comprised the analysis of the final published project reports and step two consisted of in-depth interviews with project leaders. Investigative criteria were developed to direct the focus for the analysis of the unobtrusive data. The criteria were systematically generated and informed by the literature of Chesterton and Cummings (2007), Datta (1997), Owen (2006), Patton (1994), Scriven (2007) and Stufflebeam (2011). These were then applied to the data sources as summarised in Step 1 (Table 1). Practicing the principles of Action Research, the output from the analyses then informed how the follow-up interview questions were posed to the project leaders for step two. For example not all data was available in the project reports and therefore both Step 1 and Step 2 questions (Table 1) were asked in the interviews.

[Insert Table 1. here]

The total number of internal projects $(N=61)$ completed since the grant schemes were established in 2007, were recorded and convenience sampling was used (Krippendorff, 2004; Marshal, 1996) to invite the participants for this research project. Interview participation was entirely voluntary, and project leaders were invited by email, in an effort to limit the risk of coercion to participate. A total of 15 project leaders (24\% response rate) accepted the invitation to be interviewed, representing projects from each of the current categories of grant schemes at the case university. This sample provided practicality in terms of the research timeframe and also gave a representative contextual perspective of recent projects. Disciplines covered by the sample projects include:

- Accounting and corporate governance

- Ancient history

- Anthropology

- Education 
- Environment and geography

- Linguistics

- Marketing and management

- Cultural studies

- Media

Further details of projects are not provided to ensure anonymity of participants. All project leaders were academic staff, with 9 female and 6 male. Each participant was interviewed once, with interviews of 30-40 minutes average duration. The interviews were recorded for analysis and the questions used were consistent.

\section{Data Analysis}

The method of analysis of the interview data was thematic (Braun and Clarke, 2006; Krippendorff, 2004). The interview transcripts were analysed using Leximancer, a computer generated method of coding texts where coding is automated by statistical processing. Using Leximancer as an analysis tool adds reliability to the data since accuracy is the strongest form of reliability (Weber, 1990). It also introduces validity. Validity refers to general applicability of results and conclusions obtained from inferences in the study. There is a concern for qualitative analysis in general that since the researcher chooses coding concepts they may tend towards making inferences. There may also be researcher bias and possible errors in their conclusions. Leximancer offers unbiased results from which to draw conclusions or, at minimum, to be used as a comparison (benchmark) of the researcher's findings and this was the role of Leximancer for this study.

The transcripts of answers to each of the interview questions (or steps - see Table 1) were grouped together and run through Leximancer. Concepts maps were produced (see Figure 2 for an example) along with a thematic summary. This process groups concepts into themes and ranks the most frequent theme first (as 100\% relevance 
and as the largest circle in the map) then displays the remaining themes with proportionality (representative) relative to each other. The resulting concept map indicates this by distance between themes, hence some concepts appear immediately next to others.

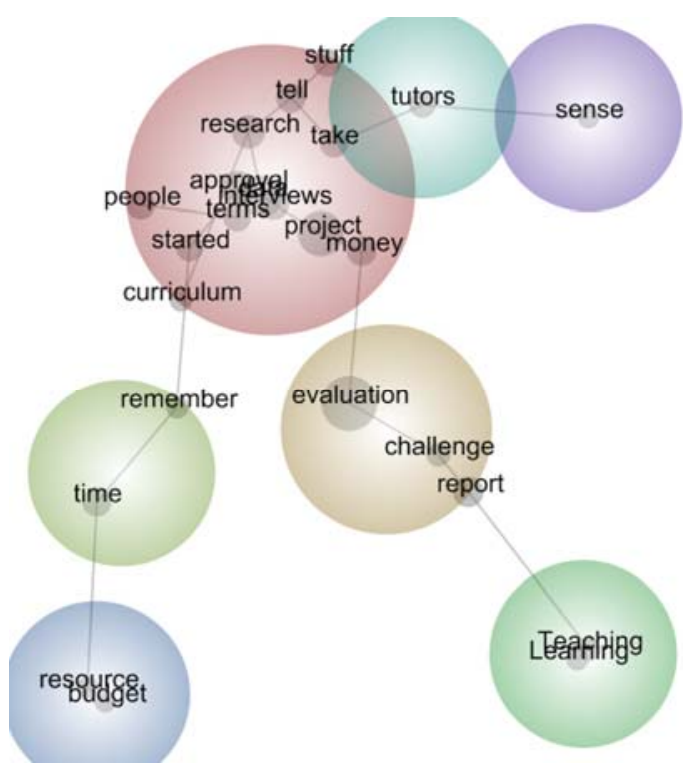

Figure 2. Leximancer concept map derived from all respondents' transcripted responses to the question: "Were there any challenges to conducting the evaluation?"

Manual coding was also carried out on the participant data using an Initial Coding approach (Charmaz, 2014) whereby the answers to each of the questions were grouped and then classified into codes as they emerged. The codes were then grouped into common themes in an iterative manner.

Next, the Leximancer themes were compared to the manually derived themes (see table 2 for an example). Employing a Focused Coding approach (Charmaz, 2014), consisting of iterative review and reorganisation of the data, six categories emerged:

1. Lack of skills - guidelines and support/resources needed

2. Initial plans too ambitious

3. Insufficient use of Stakeholders' knowledge and expertise 
4. Insufficient money/budget - to pay for extra help or input when needed i.e. admin support

5. No feedback at any stage in the project

6. Lack of time
a. to plan
b. for reflection/learning
c. too busy with teaching and other demands

Triangulation was then achieved through interrogating these categories against the literature and through this process condensed to four themes:

1. conceptualizations, particularly with the overlap between evaluation and research;

2. capability building within the sector;

3. resourcing in terms of time and money; and

4. an action oriented approach to evaluation.

Table 2. Comparison of themes (Leximancer generated vs. manually classified). Example from one question.

\begin{tabular}{|c|c|c|}
\hline \multirow{2}{*}{ Question } & \multicolumn{2}{|c|}{ Themes } \\
\hline & Leximancer generated & Manually classified \\
\hline $\begin{array}{l}\text { Were there any } \\
\text { challenges to } \\
\text { conducting the } \\
\text { evaluation? }\end{array}$ & $\begin{array}{l}\text { Project } 100 \% \\
\text { Evaluation 33\% } \\
\text { Time 10\% } \\
\text { Learning 6\% } \\
\text { Tutors 5\% } \\
\text { Budget } 4 \%\end{array}$ & $\begin{array}{ll}\text { - } & \text { Time } \\
\text { - } & \text { Money } \\
\text { - } & \text { Administration/resources } \\
\text { - } & \text { Conflation of research } \\
& \text { issues, not evaluation }\end{array}$ \\
\hline
\end{tabular}




\section{Results and Discussion}

The final four learning and teaching project evaluation themes that resulted from the coding process were: conceptualisation, capability building, resources and approach. Each theme is now explored to investigate whether praxis is achieved, that is, is the practice of evaluation of learning and teaching projects in higher education aligned with theory. The discussion is supported with verbatim quotes from the project leaders (PL).

\section{Conceptualisation}

It was evident from the interviews with project leaders that there was some confusion over what was being evaluated (outcome, product, program or process) as well as the purpose of the evaluation (Stufflebeam, 2011). To some $(n=6)$, evaluation was simply an exercise in quality assurance and therefore held a negative connotation: "I'm nervous about being evaluated ... about whether it was me being evaluated, whether the project was of a sufficient standard" (PL12). Others used evaluation as a means of learning and were more positive in their discussions: "I think it's really valuable to actually evaluate and review teaching practices and pedagogies and all that kind of thing in a systematic way, and write them up" (PL2) and then went on to state "if you're going to be a reflective teacher, that's great, but let's look at it on a more systematic level, and also inform other people of what you're doing". This is an example of using evaluation to move along 'a path of learning that is both intentional and transformative' (Preskill and Torres, 2000, p.35). Connotations about evaluation may originate from the project leader's own experience of evaluation (Christie, 2003): “Because I'm interested in evaluation and I've been involved in very large projects that have had an external evaluation, I could do that myself, if you like. So monitoring all the way along and making changes as required" (PL3). They may also arise from the absence of influence 
and direction, when the funding application doesn't specify what or how to evaluate only that it should be carried out.

Participants were unable to differentiate between evaluation, research and project outcomes. In ten of the interviews, there were numerous instances where the questions about evaluation were either misinterpreted or misunderstood, and participants' answers focused on the project or the research being conducted. For example when asked if the evaluation ran as planned some project leaders replied with information as to why the project did not go to plan. "In our project, we did not get robust data from the interviews as the participants were shy and just gave yes no answers" (PL4) and "Because of systems and processes in the University around HR (Human Resources) and appointment of staff, the project didn't really go as intended" (PL5). When asked to name challenges to conducting the evaluation, participants instead named reasons why the research or project was delayed or unsuccessful.

\footnotetext{
Also we hoped to have a Research Assistant (RA) to do the interviews but that money for the RA had to be spent on transcription and we had to conduct the interviews ourselves. So basically more time was required by the project team to complete the project. (PL4)
}

This conceptual confusion continued throughout the questioning about key evaluation questions. Most project leaders appeared unaware of the importance of these and one project leader (PL5) stated that key evaluation questions were implicit in what they were doing but had not stated them formally anywhere. There was also confusion over the word 'review'. When asked if their evaluation plans had been reviewed, participants immediately began to discuss feedback (or lack of it) on the project (either via reports or project outcomes). "Not formally reviewed but we consulted with an [expert] about the project" (PL11). Similarly when asked about evaluation results, project leaders discussed research results, again indicating that the nuance between research and 
evaluation was not clear or at least indicated that their familiarity lay with research and not evaluation. "So, in that sense, we are contributing to a body of literature that says that [the evaluand] can be used effectively to support student learning" (PL6). This is understandable, considering the strong focus on research in academia, and therefore it becomes 'natural' to talk about research outputs.

Another area of confusion arose when discussing utility of evaluation findings. Whilst eleven project leaders answered that yes the evaluation results were useable, only one or two project leaders were able to clearly articulate how, for example PL7 explained how formative results guided the project and final results were incorporated into a national grant proposal for a subsequent project.

Upon probing the level of stakeholder involvement, there was confusion: over terminology, and over the importance of making a demarcation between primary and secondary stakeholders. This finding is a concern as it is unlikely that an evaluation can meet the needs of all stakeholders and should be designed with the correct stakeholder group in mind (Chesterton and Cummings, 2007). If this is not done, then evaluation efforts may be misdirected.

No project leader was able to name the audience for their evaluations. Identification of the audience for the evaluation is crucial at the beginning of the evaluation so that decisions can be made about what to evaluate and how to report on the evaluation (Stufflebeam, 2011). In internally funded learning and teaching projects, the audience will include the funding body but it is unlikely that the funding body will also hold a stake in a particular project. This confusion between stakeholders and audiences leads to the inevitable situation where evaluation results are not useable and project leaders become disenfranchised with the purpose of evaluation, stating evidence of disinterest in results. "But appalling, you know. Clearly nobody is interested or cares 
or has a priority to follow up with, well, what can we do with this? That was kind of my fear, that, if I wanted to get any traction, I was going to be the only one" (PL12).

These differing conceptualisations impact the praxis of evaluation. Further investigation into the factors that inhibit the relationship between evaluation theory and practice is now called for.

\section{Capability building}

One explanation for the confusion around terminology and stakeholder and audience identification could be conceptual conflation. Academic teaching staff are highly conversant in the processes and value of evaluation of their own teaching and are able to describe how these evaluation results contribute to the quality assurance and enhancement processes (Birbeck, 2010; Flowers and Kosman, 2008; Kek, et al., 2009; Rodriguez et.al., 2012). However, the results of this study indicate a lack of translation of these practices from a teaching to a project context. This is confirmed by the responses of the project leaders when asked if their teams had the sufficient skills to evaluate the project with over half admitting that they did not.

Should academics be expected to be good evaluators? They are expected to have teaching and research skills but not all academics have the skills to be effective project managers and/or evaluators and rely on project managers. “...(T)here'd be a research assistant and we say, can you manage this? They wouldn't have that project management perspective or experience including the importance of evaluation" (PL3). Evaluation is best undertaken as a team approach using an evaluation expert and a content specialist (that is, an academic). Evaluators are seen as methodologists and brokers, acting as an interface between the content expert and the stakeholders (Worthern and Sanders, 2011). This position may be relevant in a larger project with funds for an external evaluator, but in the smaller projects investigated for this project, 
the evaluation skills need to be found from within the project team. If project members are yet to develop project evaluation skills, then support is needed to enable them to develop a capacity for project evaluation. A number of participants stated that they would welcome more support on evaluation.

For participants in this study, the evaluation frameworks or approaches came from participants' prior experience with evaluation (Christie, 2003). Those who were new to the learning and teaching project evaluation field were not as well versed in evaluative research as some of the project leaders who had prior experience on learning and teaching projects. An important distinction was made by PL3 who said that it was how the project manager used the evaluation framework that was more important than which framework was used (when asked about effectiveness of the chosen framework). Without support or guidance on how to conduct evaluation, these 'novices' risk succumbing to the notion (according to many participants in this study), that there is not enough time to do any evaluation. If the final report template does not stipulate the need for evaluation by requiring the reporting of details specific to evaluation then there is no perceived need to be stringent in carrying out evaluation. "One gets the feeling that we are just going through the motions of providing a report" (PL15). Capability building aligns conceptually with the main theme resulting from the Leximancer analysis, of 'Support' "But yes the idea of having some people who are on standby, potential evaluators for internal projects, I think that would work, definitely" (PL1). It also links to having an evaluation plan. Only three projects achieved an alignment between having an evaluation plan and having this plan reviewed. Alignment was also called for between the plan and process of evaluation: "we need some constructive alignment between the evaluation plan and the evaluation itself" (PL15). Comments from project leaders indicate that lack of alignment was due to lack of time. If well planned, the 
evaluation should be incorporated into the project timeline, and the review/feedback of this plan ought to indicate to such novice evaluators where and what to look out for to ensure the evaluation not only takes place but is effective.

Other examples highlighting a lack of understanding of, or skills in, evaluation were evident from the findings. Only four project leaders could name an evaluation framework. From this we could infer that the others didn't know the names of any frameworks or perhaps they did not understand the relevance of using one. When discussing evaluation utilization, many participants were unsure of how the evaluation results would be used (and had not planned for this). However most project leaders, $(n=11)$, discussed usability of project results rather than results of any evaluation.

On the subject of generalisability of evaluation results, again there was a lack of understanding of the importance of this. One participant stated, "I have problems with this. If you generalise something then you are homogenising things. Disciplines often have their own methodology and specific processes" (PL14). Whilst this is true, the value of generalising evaluation results is that recommendations can be made, one of the functions of evaluation.

Without evaluation, how can we ensure that quality assurance or more importantly, quality enhancement is taking place? "Because to me that's [evaluation] really a key, otherwise you'll end up with all these funny little helium balloon projects that don't really lead anywhere" (PL3) and evaluation has a role in closing the loop on the quality cycle. Evaluation is a critical point in this cycle if we are aiming for continuous improvement and achieving accountability.

\section{Resourcing time and money}

Lack of time to engage with evaluation emerged as a strong theme in this study. It was also present as an overarching factor in a recent critique of the learning and teaching 
project evaluation literature [name deleted to maintain integrity of the review process].

That review found that many of the complex evaluation approaches reported are not suitable to smaller scale projects (Stoner et al., 2012). Or, simply, there is not enough time available to implement the required evaluation measures (Bamberger et al., 2004; Bearman et al., 2008; Harris et al., 2010; Ryan, Chandler and Samuels, 2077). This relates to our earlier discussion, as time is required to build capacity in evaluation, but if we are looking at small-scale projects perhaps of only 12-18 months duration there may not be adequate time to invest in such measures.

PL8 reflects "It could have been done better if more time or resources were available - but we managed to deliver the main message". However we could counter that evaluation scoping should have been taken into account during the project planning phase and it may be this lack of expertise that is the real 'culprit' and not actually lack of time. This planning stage is crucial for the successful completion of the evaluative process as described in Figure 1. "Could have been more realistic of timing of project itself. Don't make evaluation an afterthought, but allow time for evaluation" (PL2).

A lack of resources (both financial and human) was repeatedly mentioned. A human resource of an "external pair of eyes" (PL2), a professional or peer review, would have been helpful in terms of offering feedback on the evaluation plan but participants questioned how this would be funded. A review stage links to the evaluation planning stage, for if this was a requirement it could be budgeted in the grant application and clearly defined in the scoping stage. The University's central support office, the Learning and Teaching Centre, was specifically identified by participants as potentially providing a review service, with the caveat that it is planned and negotiated at the start of a project.

\section{An action-oriented approach}


Three project leaders were able to name the evaluation approach they used: a developmental approach, an action research approach and a participatory action research approach. Theoretically the last two are research approaches and not specifically evaluation approaches however as discussed earlier in this paper it is fair to assume that the theoretical worldviews or paradigms prevalent in social science research can also be applied to evaluative enquiry. These approaches fit well with the idea of collecting formative evaluation data to inform improvements as well as the standard summative evaluation data that may serve as an accountability measure. Wadsworth (2011) calls this MERI (monitoring, evaluation, research and improvement). This approach also offers the potential of a good fit with the higher education sector (Sheard and Markham, 2005) where action research is commonplace (McNiff, 2001) in some disciplines. It can be applied to evaluation with the benefit of increased learning and development opportunities for all involved parties (Harris et al., 2010). This was noted by one project leader:

...researchers, actually, start with some particular objectives, but then through the research process, they find out that the reality might be something else. Therefore, you need to adjust yourself and base your evaluation of this situation and the issues that you're faced with. (PL4)

The form an evaluation will take, influences the role of the stakeholders and study audiences for a project. The role of stakeholder 'buy-in' is well documented for successful evaluation results (Geva-May and Peretz, 1991; Johnson et. al., 2009; Mayhew, 2011; Shadish, Cook and Leviton, 1991; Shula and Cousins, 1997; Stern, 2004) and was acknowledged in a number of the project leader's comments, for example "I'm wary to get too many stakeholders involved because then it becomes this huge monster. Though if you don't get enough then the project will not succeed" (PL13). A developmental approach to evaluation would allow for stakeholder 
involvement at different stages of the evaluative process and again encourage learning from the project. Another strategy would be to encourage the project leaders to practice critical reflection as part of the evaluation data collection stage and as part of the Action Research cycle.

If you know where you are going, you can keep an eye on the journey and then when you get there you will be able to look back and see what happened to help you get there. Its part of being a reflective practitioner. (PL2)

\section{Implications for Evaluation Practice and Future Research}

How can we use the knowledge gained through the themes emerging from this study to enable evaluation praxis in internally funded learning and teaching projects?

Sustainable and successful approaches to evaluation need to be showcased with the project management community in the sector.

Listening to the voices of the learning and teaching project leaders, and drawing on our research findings, we are able to extrapolate and identify a series of strategies for developing capacity across the sector for project evaluation. The strategies, with a focus on internally funded learning and teaching projects, include the development and provision of:

- Support, possibly from a centralized unit, including succinct resources and their dissemination on learning and teaching project evaluation

- Information about evaluation frameworks, including their benefits

- A time allocation for evaluation in future and ongoing project plans as well as provision to revisit the project and assess impact

- Models of how to incorporate evaluation into the research cycle

- Constructive feedback on evaluation reports from the University and its funding body 
- A requirement that makes evaluation and its reporting compulsory

- Support for identifying stakeholders and study audiences

- Networking opportunities to disseminate learnings from project evaluations

There is certainly some resistance to conducting evaluation, evidenced in these shorter projects, "People say is it just another hoop you've got to jump through. Is it more red tape added to what is already a complex process?" (PL12). And

If an evaluator is going to have the final say, in the summative sense, of what's actually gone on through the project, then people in the project team might not sometimes put forward their views, or be disinclined to say no, we're not doing it that way, because they don't want to impact on the final outcomes, if that outcome is loaded in terms of accountability measures. (PL6)

Other perceptions were also evident in the data, for example

I think in education, particularly in stuff that's fairly close to the action research curriculum development stuff, you kind of get money by promising to do things the university wants you to do and if you don't get out results that look like the sorts of things the university want, you may not get money in the future. (PL1)

Further investigation into these perceptions of evaluation and how they influence praxis is needed.

\section{Conclusion}

Our recent critique of the existing literature highlighted the misalignment between evaluation theory and practice of learning and teaching project evaluation in the sector and this study confirms this proposition. Four themes were evident in the data from fifteen learning and teaching projects: conceptualizations, particularly with the overlap between evaluation and research; capability building within the sector; resourcing in terms of time and money; and an action oriented approach to evaluation. The project 
leader's perception and conceptualization of evaluation can inhibit the relationship between theory and practice.

A limitation to this study is that it was based at one university with a limited number of projects studied $(n=15)$. A recommendation for future research would be to examine the transferability and generalisability of the findings by investigating the evaluation praxis across multiple institutions, and thus a larger sample.

Further to this study on small projects, we invite colleagues to undertake investigation into evaluation as it is applied in large-scale learning and teaching projects in the higher education sector. We also ask the sector to answer the call made by project leaders of supporting them as project evaluators: through the provision of resources, frameworks, models, networking opportunities and valuing evaluation by mandating its role in projects and then providing constructive feedback.

\section{References}

Alexander, S. (1999), “An evaluation of innovative projects involving communication and information technology in higher education”, Higher Education Research and Development, Vol. 18 No. 2, pp. $173-183$.

Alexander, S. and Hedberg, J.G. (1994), “Evaluating technology-based learning: Which model?”, Proceedings of the IFIP TC3/WG3.2 Working Conference on the Seign, Implementation and Evaluation of Interactive Multimedia in University Settings: Designing for Change in Teaching and Learning, Elsevier Science Inc., New York, NY, USA, pp. 233-244.

Alkin, M.C. (2011), Evaluation Essentials: From A-Z, The Guildford Press, New York, NY.

Alkin, M.C. and Taut, S.M. (2003), "Unbundling Evaluation Use”, Studies in Educational Evaluation, Vol. 29 No. 2003, pp. 1-3.

Bamberger, M., Rugh, J., Church, M. and Fort, L. (2004), “Shoestring evaluation: Designing impact evaluations under budget, time and data constraints", American Journal of Evaluation, Vol. 25 No. 1, pp. 5-37. 
Bearman, M., Lawson, M., Lindley, J., Kiegaldie, D., Jolly, B. and Kotsanas, G. (2008), “Evaluation of an inter-institutional granting scheme for collaboration in educational technologies", HERDSA 2008 : Engaging Communities, HERDSA, 2008, pp. 53-65.

Birbeck, D. (2010), "Benchmarking and peer review of teaching practice for the purpose of evidencing excellence in teaching and learning”, Ergo, Vol. 1 No. 3, pp. 5-10.

Braun, V. and Clarke, V. (2006), "Using thematic analysis in psychology", Qualitative Research in Psychology, Vol. 2006 No. 3, pp. 77-101.

Charmaz, K. (2014), Constructing Grounded Theory, 2nd edn, SAGE Publications.

Chesterton, P. and Cummings, R. (2007), “ALTC Grants Scheme - Evaluating projects”, available at: http://www.olt.gov.au/evaluation (accessed 14 July 2014).

Christie, C.A. (2003), "What Guides Evaluation? A Study of How Evaluation Practice Maps onto Evaluation Theory", New Directions for Evaluation, Vol. 97, pp. 7-35.

Cresswell, J.W. and Plano-Clarke, V.L. (2011), Designing and conducting Mixed Methods Research, Sage, Thousand Oaks.

Cybulski, J. (2010), Building academic staff capacity for using eSimulations in professional education for experience transfer, Deakin University.

Datta, L. (1997), “A pragmatic basis for mixed-method designs”, New Directions for Evaluation, Vol. 1997 No. 74, pp. 33-46.

Flowers, J. and Kosman, B. (2008), “Teaching matters : developing indicators of teaching quality, a comparative study", In Canberra Reference Group (Ed.), AUQF2008 : Quality and standards in higher education: making a difference, Australian Universities Quality Agency (AUQA): Melbourne, Canberra, Australia, pp. 32-38.

Frolich, N. (2011), "Muti-layered accountability, performance-based funding of universities”, Public Administration, Vol. 89 No. 3, pp. 840-859.

Geva-May, I. and Peretz, H. (1992), "Serving the needs of various groups of stakeholders", Studies in Educational Evaluation, Vol. 17 No. 1, pp. 137-149.

Harris, L., Jones, M. and Coutts, S. (2010), "Partnerships and learning communities in work-integrated learning: designing a community services student placement program”, Higher Education Research \& Development, Vol. 29 No. 5, pp. 547-559. 
Huber, E. \& Harvey, M. (2013), “Time to participate: Lessons from the literature for learning and teaching project evaluation in higher education", Studies in Educational Evaluation, Vol. 39 No. 4, pp. 240-249.

Johnson, K., Greenseid, L.O., Toal, S.A., King, J.A., Lawrenz, F. and Volkov, B. (2009), "Research on Evaluation Use: A Review of the Empirical Literature From 1986 to 2005”, American Journal of Evaluation, Vol. 30 No. 3, pp. 377-410 http://aje.sagepub.com/content/30/3/377.abstract (accessed 6 October 2013).

Kazi, M.A.F. (Ed.). (2003), “Introduction”, Realist evaluation in practice, SAGE Publications Ltd., pp. $2-10$.

Kek, M., Hunt, L. and Sankey, M. (2009), “Closing the loop : a case study of a post-evaluation strategy”, AUQF2009 : internal and external quality assurance : tensions and synergies, Australian Universities Quality Agency, Alice Springs, pp. 100-105.

Krippendorff, K. (2004), Content analysis: an introduction to its methodology, 2nd edn, Sage Publications, Inc., Thousand Oaks, California.

Mark, M.M., Henry, G.T. and Julnes, G. (1998), “A Realist Theory of Evaluation Practice”, New Directions for Evaluation, Vol. 1998 No. 78, pp. 3-32.

Mark, M.M. and Shotland, R.L. (1987), “Multiple Methods in Program Evaluation”, New Directions for Program Evaluation, Vol. 34.

Marshal, M.N. (1996), “Sampling for qualitative research”, Family Practice, Vol. 13 No. 6, p. 4.

Mayhew, F. (2011), “Integrating the Funder-Fundee Relationship into a Model of Evaluation Utilization”, Journal of Multidisciplinary Evaluation, Vol. 7 No. 16, p. 19.

McNiff, J. (2001), Action Research: Principles and practice, 2nd edn, Routledge, London.

Oliver, M., MacBean, J., Conole, G. and Harvey, J. (2002), “Using a toolkit to support the evaluation of learning”, Journal of Computer Assisted Learning, Vol. 18 No. 2, pp. 199-208.

Owen, J.M. (2006), Program evaluation. Forms and approaches, Allen and Unwin.

Patton, M. (1994), “Developmental evaluation”, American Journal of Evaluation, Vol. 15 No. 3, pp. 311319.

Phillips, R. (2002), Learning-centred evaluation of computer-facilitated learning projects in higher education: Outcomes of a CUTSD staff development grant, Canberra: Committee for University 
Teaching and Staff Development Project, available at:

http://www.tlc.murdoch.edu.au/project/cutsd01.html (accessed 9 March 2013).

Preskill, H. and Torres, R.T. (2000), “The Learning Dimension of Evaluation Use”, New Directions for Evaluation, Vol. 88, pp. 25-37.

Rodriguez, M.D.L., Lopez, L.B., Perez, A.M.F., Leon, E.F. and Varo, M.E. Flores. (2012), “Evaluation of the contribution of questionnaires to the improvement in teaching of economic theory in the European higher education space", EDULEARN12, Presented at the 4th International Conference on Education and New Learning Technologies, Barcelona, Spain, pp. 1856-1863.

Ryan, K.E., Chandler, M. and Samuels, M. (2007), "What should school-based evaluation look like?", Studies in Educational Evaluation, Vol. 33 No. 3-4, pp. 197-212.

Scriven, M. (2007), “Key Evaluation Checklist”, Evaluation Checklists Project, available at: http://www.wmich.edu/evalctr/checklists (accessed 20 May 2012).

Shadish, W., Cook, T. and Leviton, L. (1980). Foundations of Program Evaluation. Theories of practice, SAGE, Newbury Park, California.

Shah, M., Nair, S. and Wilson, M. (2011), "Quality assurance in Australian higher education: historical and future development”, Asia Pacific Education Review, Vol. 12 No. 3, pp. 475-483.

Sheard, J. and Markham, S. (2005), "Web-based learning environments: developing a framework for evaluation", Assessment \& Evaluation in Higher Education, Vol. 30 No. 4, pp. 353-368.

Shula, L. and Cousins, B. (1997). "Evaluation use: Theory, Research, and Practice Since 1986”, American Journal of Evaluation, Vol. 1997 No. 18, p. 195.

Southwell, D., Gannaway, D., Orrell, J., Chalmers, D. and Abraham, C. (2005), Strategies for effective dissemination of project outcomes, The University of Queensland and Flinders University, p. 113.

Stern, E. (2004), "Philosophies and types of evaluation research", in Descy, P. and Tessaring, M. (Eds.), The foundations of evaluation and impact research, Third report on vocational training research in Europe: background report, Office for Official Publications of the European Communities, Luxembourg.

Stevens, F., Lawrenz, F. and Sharp, L. (1993), User-Friendly Handbook for Project Evaluation: Science, Mathematics, Engineering, and Technology Education. ( No. NSF-93-152), National Science Foundation, Washington, DC. Directorate for Education and Human Resources, p. 111. 
Stoner, J.B., Meaden, H., Angell, M.E. and Daczewitz, M. (2012), "Evaluation of the Parent-implemented Communication Strategies (PiCS) project using the Multiattribute Utility (MAU) approach", Educational Assessment, Evaluation and Accountability, Vol. 24 No. 1, pp. 57-73.

Stufflebeam, D.L. (2011), “Meta-evaluation”, Journal of MultiDisciplinary Evaluation, Vol. 7 No. 15, available at: http://survey.ate.wmich.edu/jmde/index.php/jmde_1/article/view/300/295 (accessed 6 October 2013).

Wadsworth, Y. (2011), Do It Yourself Social Research, 3rd edn, Allen \& Unwin, Crows Nest.

Weber, R.P. (1990), Basic content analysis, 2nd edn, Sage University Paper Series on Quantitative Applications in the Social Sciences, 49, Sage, Newbury Park, CA.

Worthern, B.R. and Sanders, J.R. (2011), “Content Specialization and Educational Evaluation: A Necessary Marriage", Journal of MultiDisciplinary Evaluation; Vol 7, No 15 (2011), Vol. 7 No. 15, available at: http://survey.ate.wmich.edu/jmde/index.php/jmde 1/article/view/307/306 (accessed 9 March 2013).

\section{Biographical Details:}

Elaine Huber is investigating the praxis of evaluation of locally funded learning and teaching projects in higher education for her $\mathrm{PhD}$ in Education at Macquarie University. Elaine also works at Macquarie's Learning and Teaching Centre as the Head of Educational Development, a role in which she indulges her other main passion, educational technologies. In addition, she is the coordinator of the Faculty Partnership Program whose project's aim to support university faculties in their strategic development of educational approaches and resources for use in teaching and learning. Using a developmental approach to project evaluation in this program allows her to align her work with her research interests.

Dr Marina Harvey convenes and teaches postgraduate students at Macquarie University on Critically Reflective Practice in Higher Education where she explores her interests in reflective practice and action research. She also convenes the Foundations (in Learning and Teaching) program.

Marina's research interests are interrelated and aligned with her teaching and professional development foci. Three main areas of interest are: developing quality learning and teaching in higher education (especially with sessional or 
casual staff, leading a national project on this), academic leadership (distributed leadership) and evaluation, assessment and feedback in higher education. 